\title{
Organic conductor: Influence of preparation temperature
}

\begin{abstract}
The conducting polypyrrole-polyethylene glycol (PPy-PEG) composite films were produced at various polymerization temperature ranging from $5{ }^{\circ} \mathrm{C}$ to $60^{\circ} \mathrm{C}$ using $1 \times 10-3 \mathrm{M} \mathrm{PEG}$, $0.20 \mathrm{M}$ pyrrole and $0.10 \mathrm{M}$ p-toluene sulfonate at $1.20 \mathrm{~V}$ (vs. SCE). The polymerization temperature of $5{ }^{\circ} \mathrm{C}$ appeared as the optimum preparation temperature showing the highest electrical conductivity of $70 \mathrm{~S} / \mathrm{cm}$ and the thermal diffusivity of $8.76 \times 10-7 \mathrm{~m} 2 \mathrm{~s}-1$. The electrical conductivity and thermal diffusivity exhibited a decreasing trend with the increase in polymerization temperature in the pyrrole solution used to prepare the composite films. The XRD results reveal that low temperature $(5 \circ \mathrm{C})$ typically results in more crystalline films, which are denser, stronger and have higher conductivity. The optical microscopy of PPyPEG shows the globular surface morphology. The surface of the of the solution side of PPyPEG film prepared at low temperatures showed a globular morphology.
\end{abstract}

Keyword: Polypyrrole,Polyethylene glycol,Thermal diffusivity, Electrical conductivity Dopant 